\title{
Uma proposta de análise do livro didático à luz da Educação Matemática Crítica
}

\author{
A proposal of analysis of the textbook in the light of Critical Mathematics \\ Education
}

\author{
Cecy Leite Alves Carreta ${ }^{1}$ \\ Elenilton Vieira Godoy²
}

\section{Resumo}

No decorrer da dissertação foi criado um instrumento de avaliação para auxiliar na investigação proposta. Esse instrumento é composto pelas principais ideias pertencentes à Educação Matemática Crítica, contendo perguntas direcionadas ao livro do aluno e ao manual do professor a respeito dos capítulos relacionados ao conceito de função, função polinomial do $1^{\circ}$ e $2^{\circ}$ graus, função exponencial e função logarítmica, todavia, 0 instrumento pode ser adaptado para qualquer conteúdo matemático, de qualquer ano escolar, uma vez que o instrumento é pautado nos conceitos estruturantes da Educação Matemática Crítica (EMC) e não nos conteúdos matemáticos. Este produto é direcionado a todos os docentes que ministram Matemática na Educação Básica e que pretendem verificar se o livro didático utilizado pode ou não contribuir para uma formação pautada na EMC. O produto será composto pelo instrumento de avaliação e a demonstração de algumas questões que fazem parte de nossa análise, a fim de verificar como ela foi desenvolvida. Portanto, o objetivo principal deste produto é auxiliar e subsidiar um olhar crítico dos docentes para os livros didáticos utilizados.

Palavras-chave: Livro Didático. Educação Matemática Crítica. Plano Nacional do Livro Didático.

\section{Abstract}

During the dissertation, an evaluation instrument was created in order to assist in the proposed research. This instrument is composed by the main ideas belonging to Critical Mathematics Education, containing questions directed to the student's book and the teacher's manual regarding the chapters related to the concept of function, polynomial function of the 1st and 2nd grades, exponential function and logarithmic function. However , the instrument can be adapted to any mathematical content of any school year, since the instrument is based on the structuring concepts of Critical Mathematical Education (EMC) and not on mathematical contents. This product is directed to all teachers who teach Mathematics in Basic Education and who want to verify if the textbook used may or may not contribute to an EMC-based training. The product will be composed by the evaluation instrument and the demonstration of some questions that are part of our analysis, in order to verify how it was developed. Therefore, the main objective of this product is to help and subsidize two critical teachers for the teaching materials used.

\footnotetext{
${ }^{1}$ Mestre em Ensino de Ciências e Matemática pela Universidade Cruzeiro do Sul (UNICSUL). Professora efetiva da EMEF Prof. Joaninha Grassi Fagundes. E-mail: cecy@hotmail.com.br.

2 Doutor em Educação pela Universidade de São Paulo (FEUSP). Professor do departamento de Matemática, do Programa de Pós-Graduação em Educação em Ciências e em Matemática (PPGECM) e do Programa de Pós-Graduação em Educação (PPGE) da Universidade Federal do Paraná (UFPR). E-mail: elenilton@ufpr.br.
} 
keywords: Textbook. Education Mathematics Critical. National Textbook Program.

\section{Apresentação}

Este produto foi construído a partir da dissertação (de mestrado profissional), intitulada "O Programa Nacional do Livro Didático. Do conceito de Função à Função Logarítmica: um olhar sociocrítico.", defendida no ano de 2017 , cujo objetivo foi investigar se a abordagem dos assuntos relacionados ao estudo do conceito de função, funções polinomiais do $1^{\circ}$ e $2^{\circ}$ graus e das funções exponenciais e logarítmicas, ao longo do primeiro ano do Ensino Médio, de alguma maneira, contemplam a tendência teórica Educação Matemática Crítica (EMC).

No decorrer da dissertação foi criado um instrumento de avaliação para auxiliar em nossa investigação. Esse instrumento é composto pelas principais ideias pertencentes à EMC, contendo perguntas direcionadas ao livro do aluno e ao manual do professor a respeito dos capítulos relacionados ao conceito de função, função polinomial do $1^{\circ}$ e $2^{\circ}$ graus, função exponencial e função logarítmica, todavia, o instrumento pode ser adaptado para qualquer conteúdo matemático, de qualquer ano escolar, uma vez que o instrumento é pautado nos conceitos estruturantes da Educação Matemática Crítica e não nos conteúdos matemáticos.

Este produto é direcionado a todos os docentes que ministram a disciplina de Matemática na Educação Básica e que pretendem verificar se os livros didáticos utilizados podem contribuir ou não para uma formação pautada na EMC. Considerando que os livros didáticos assumem um papel de extrema relevância no ensino, uma vez que é o principal instrumento de auxílio dos professores ao planejarem suas aulas, consideramos oportuno o olhar crítico do professor para esse material. De acordo com Gérard e Roegiers (1998) o livro didático é um instrumento impresso que tem como finalidade o processo de aprendizagem. Neste sentido, o livro didático é um objeto cultural fundamental no processo de escolarização. 
O produto que nos propomos a elaborar será composto pelo instrumento de avaliação e pela análise de três Situações. Selecionamos uma Situação de cada livro e de cada Referencial (Matemática Pura, Semirrealidade e Realidade). Portanto, o objetivo principal deste produto é auxiliar e subsidiar um olhar crítico dos docentes para os livros didáticos de Matemática, bem como para outros materiais curriculares.

\section{Educação Matemática Crítica}

A Educação Matemática Crítica (EMC), conforme Araújo (2009), tem o intuito de formar cidadãos que utilizem o conhecimento matemático para compreender aspectos presentes na sociedade democrática (política, economia, educação etc.). Segundo Skovsmose (1996) a EMC se interessa pela preparação dos alunos para o exercício da cidadania de forma democrática em uma sociedade altamente tecnológica, uma vez que "a humanidade está envolvida pela tecnologia. A sociedade e a tecnologia tornaram-se os aspectos dominantes da civilização" (SKOVSMOSE, 2001, p. 76-77). Concordamos com Skovsmose (2001) ao acreditar que a democracia acopla muito mais do que uma relação de distribuição de direitos e deveres. A ideia de democracia também abrange a existência de uma atribuição de competências na sociedade e, neste sentido, a democracia ocorre quando os indivíduos participantes da sociedade se envolvem ativamente no corpo social. Essa é a concepção que o ensino deve buscar para, minimamente, pensar numa Educação Crítica (EC).

Neste sentido, a ideia da EMC, proposta por Skovsmose, foi fundamentada nos termos-chave da EC, quais sejam competência crítica, distância crítica e engajamento crítico (SKOVSMOSE, 2001). Para que a EC aconteça Skovsmose (2001) acredita que os estudantes necessitam envolver-se no processo educacional, assumindo o controle de sua aprendizagem e assim desenvolver a competência crítica; também é importante manter uma distância crítica, ou seja, o professor junto com o aluno analisa os conteúdos presentes no currículo a fim de verificar a viabilidade e importância do assunto; e por fim, os alunos devem ter um 
engajamento crítico, isto é, devem se interessar pelo assunto abordado de forma espontânea para que os mesmos se envolvam no processo educativo.

A EMC inclusive tem o intuito de desenvolver a habilidade da competência democrática no estudante definida por Skovsmose (2001) como sendo a competência de saber avaliar e analisar as pessoas que estão no poder representando a população, isto é, "[...] o desenvolvimento dessa competência como uma condição fundamental para a vida democrática". (SKOVSMOSE, 2001, p. 76). Essa competência democrática é desenvolvida por meio da atitude democrática, logo para se desenvolver essa competência é necessário que a educação seja alicerçada na democracia.

"Isso significa que competência democrática é uma característica socialmente
desenvolvida da competência que as pessoas, ao serem governadas, devem
possuir, de modo que possam ser capazes de julgar os atos das pessoas
encarregadas de governar. Essa competência variará de acordo com as
estruturas da sociedade" (SKOVSMOSE, 2001, p. 56).

A Matemática tem uma atribuição primordial para a evolução da competência democrática, visto que para o indivíduo desenvolver uma competência democrática na sociedade atual, em outras palavras, em uma sociedade altamente tecnológica, é necessário ter conhecimento matemático para compreender os aspectos presentes na tecnologia da informação (Skovsmose, 2001).

Em uma sociedade altamente tecnológica, o conhecimento matemático parece construir uma parte central da competência democrática. "Para estar apto a participar de obrigações e direitos democráticos, é necessário estar apto a entender os princípios centrais dos mecanismos do desenvolvimento da sociedade" (SKOVSMOSE, 2001, p. 95). Para Skovsmose (2001) a competência democrática está em grande medida baseada no conhecimento reflexivo, isto é, embora a tecnologia tenha um papel crucial na formação da sociedade, não é o conhecimento tecnológico que constitui a competência democrática. "A tese fundamental em relação ao conhecimento tecnológico e reflexivo é a de que o conhecimento tecnológico, em si, é incapaz de predizer e analisar os resultados de sua própria produção; reflexões são necessárias" (SKOVSMOSE, 2001, p. 85). 
$\mathrm{Na}$ verdade a integração da Matemática à Tecnologia necessita de três tipos de conhecimentos: o conhecimento matemático, o conhecimento tecnológico ou conhecimento pragmático, que é o conhecimento que indica como construir e utilizar modelos matemáticos e o conhecimento reflexivo "que deve ser interpretado como um referencial teórico mais conceitual, ou metaconhecimento, para que se possam discutir a natureza dos modelos e o critério usado em sua construção, aplicação e avaliação" (SKOVSMOSE, 2001, p. 59). Skovsmose (2001) acredita que é função da educação desenvolver a competência democrática, preparando para uma cidadania crítica.

Em conclusão, a escola deve garantir aprendizagens fundamentais (baseadas pelos três conhecimentos) para a formação de cidadãos críticos, autônomos, participativos e presentes em situações importantes, sendo capazes de atuar com competência democrática na sociedade atual.

\subsection{Cenários para investigação}

Baseado na forma como as aulas de Matemática são organizadas, Skovsmose (2000) diferenciou dois tipos de aulas (paradigma do exercício e cenário para investigação). O paradigma do exercício está baseado no ensino tradicional, o professor é visto como detentor do saber e os alunos recebem o conteúdo pronto e reproduzem quando solicitado, "o conteúdo é ensinado aos alunos e alunas por intermédio de explicações orais e exercícios de fixação". (FAUSTINO; PASSOS, 2013, p. 64). As autoras ainda afirmam que, de modo geral, os livros didáticos utilizam essa abordagem, pois esses livros são produzidos por autoridades externas à sala de aula. Skovsmose (2000) sustenta que as aulas apoiadas no paradigma do exercício têm o pressuposto de que há somente uma resposta correta, e com isso os alunos são impedidos de questionarem a relevância de determinado exercício.

O paradigma do exercício é o oposto de uma abordagem investigativa. Apoiando-nos em Skovsmose (2000) o cenário para investigação é um ambiente propício ao trabalho de investigação, o qual deve convidar os alunos a indagarem, investigarem e formularem questões. 
Transpor do paradigma do exercício para o cenário para investigação contribui para o enfraquecimento da autoridade absolutista na sala de aula, como ocorre no método tradicional do ensino da Matemática, além disso, contribui para o engajamento dos alunos no processo de aprendizagem. Skovsmose (2000) desenvolve uma matriz a partir da combinação dos três referenciais (Matemática Pura, Semirrealidade e Realidade) e a diferenciação entre o paradigma do exercício e o cenário para investigação. A matriz é composta por seis diferentes tipos de ambientes de aprendizagem.

Figura 1- Ambientes de aprendizagem

\begin{tabular}{|l|c|c|}
\hline & Exercícios & Cenário para Investigação \\
\hline Referências à matemática pura & $(1)$ & $(2)$ \\
\hline Referências à semirrealidade & $(3)$ & $(4)$ \\
\hline Referências à realidade & $(5)$ & $(6)$ \\
\hline
\end{tabular}

Fonte: Skovsmose (2000).

Em conformidade com o autor, o ambiente tipo (1) é constituído pelos exercícios da Matemática Pura com resolução direta. O ambiente tipo (2) por problemas presentes na Matemática Pura, porém esses problemas envolvem números e figuras geométricas (ARAÚJO, 2009). O ambiente tipo (3) apresenta situações fictícias utilizadas para a criação de exercícios. O ambiente tipo (4) também é composto por situações fictícias, porém essas situações convidam os alunos a fazerem explicações e explorações. O ambiente tipo (5) é composto por situações reais que são apresentadas por meio de problemas fechados. Por fim, o ambiente tipo (6) é formado por situações reais abordadas por uma perspectiva aberta, a qual se torna possível os alunos produzirem diferentes conceitos e significados.

Em nossa pesquisa temos a preferência para situações reais que envolvam a dimensão política da Matemática, porém, o autor sustenta a importância de os estudantes perpassarem os três referenciais. "Quando os alunos assumem o processo de aprendizagem de exploração e explicação, o cenário para investigação passa a constituir um novo ambiente de aprendizagem. No cenário para investigação, os alunos são responsáveis pelo processo" (SKOVSMOSE, 
2000, p. 6). Desse modo, consideramos que o cenário para investigação contribui para o desenvolvimento da Competência Crítica.

\section{Produto Educacional}

O instrumento de coleta de dados utilizado para analisar os livros didáticos e os seus respectivos manuais do professor foi construído por nós e procurou contemplar as principais características da Educação Matemática Crítica.

\subsection{Instrumento de avaliação}

Tabela 1: Escala x Descritor

\begin{tabular}{|l|l|l|}
\hline Escala & Descritor & Percentual \\
\hline 0 & Não aborda & $0 \%$ \\
\hline 1 & Abordagem insatisfatória & $1 \%$ a $25 \%$ \\
\hline 2 & Abordagem parcialmente satisfatória & $26 \%$ a $50 \%$ \\
\hline 3 & Abordagem satisfatória & $51 \%$ a $75 \%$ \\
\hline 4 & Abordagem Altamente Satisfatória & $75 \%$ a $100 \%$ \\
\hline
\end{tabular}

Fonte: Elaboração dos autores

1) Classifique, de acordo com a escala contida na Tabela 1, se o manual do professor apresenta informações associadas aos termos-chave competência crítica, distância crítica e engajamento crítico.

\begin{tabular}{|l|c|c|c|}
\hline \multicolumn{1}{|c|}{ Manual do professor } & $\begin{array}{c}\text { Competência } \\
\text { Crítica }\end{array}$ & $\begin{array}{c}\text { Distância } \\
\text { Crítica }\end{array}$ & $\begin{array}{c}\text { Engajamento } \\
\text { Crítico }\end{array}$ \\
\hline Textos sobre educação & & & \\
\hline Sugestões de leitura & & & \\
\hline Textos específicos & & & \\
\hline Resolução de exercícios & & & \\
\hline
\end{tabular}

2) Classifique, de acordo com a escala contida na Tabela 1, se as diferentes seções do livro didático exploram situações que desenvolvam e aperfeiçoam, junto aos alunos, a habilidade de criar modelos matemáticos.

\begin{tabular}{|l|l|}
\hline Seções & Classificação \\
\hline Textos introdutórios & \\
\hline Textos específicos & \\
\hline Exercícios & \\
\hline Curiosidades & \\
\hline Informações adicionais & \\
\hline
\end{tabular}

3) Classifique, de acordo com a escala contida na Tabela 1, se as diferentes seções do livro didático exploram situações que desenvolvam e aperfeiçoam, 
junto aos alunos, a habilidade de resolver problemas reais, os quais eles possam investigar ou desenvolver maneiras criativas de estruturá-los.

\begin{tabular}{|l|l|}
\hline Seções & Classificação \\
\hline Textos introdutórios & \\
\hline Textos específicos & \\
\hline Exercícios & \\
\hline Curiosidades & \\
\hline Informações adicionais & \\
\hline
\end{tabular}

4) Classifique (Avalie), de acordo com a escala contida na Tabela 1, as estratégias metodológicas utilizadas pelo livro didático para desenvolver 0 conceito de "Função".

\begin{tabular}{|l|l|}
\hline Estratégia Metodológica & Classificação \\
\hline $\begin{array}{l}\text { Referências à Matemática } \\
\text { Pura }\end{array}$ & \\
\hline Referências à semirrealidade & \\
\hline Referências à realidade & \\
\hline
\end{tabular}

5) Classifique (Avalie), de acordo com a escala contida na Tabela 2, as estratégias metodológicas utilizadas pelo livro didático para desenvolver o conceito de "Função Afim".

\begin{tabular}{|l|l|}
\hline Estratégia Metodológica & Classificação \\
\hline $\begin{array}{l}\text { Referências à Matemática } \\
\text { Pura }\end{array}$ & \\
\hline Referências à semirrealidade & \\
\hline Referências à realidade & \\
\hline
\end{tabular}

6) Classifique (Avalie), de acordo com a escala contida na Tabela 2, as estratégias metodológicas utilizadas pelo livro didático para desenvolver 0 conceito de "Função Quadrática".

\begin{tabular}{|l|l|}
\hline Estratégia Metodológica & Classificação \\
\hline Referências à Matemática Pura & \\
\hline Referências à semirrealidade & \\
\hline Referências à realidade & \\
\hline
\end{tabular}

7) Classifique (Avalie), de acordo com a escala contida na Tabela 2, as estratégias metodológicas utilizadas pelo livro didático para desenvolver o conceito de "Função Exponencial".

\begin{tabular}{|l|l|}
\hline Estratégia Metodológica & Classificação \\
\hline Referências à Matemática Pura & \\
\hline Referências à semirrealidade & \\
\hline Referências à realidade & \\
\hline
\end{tabular}

8) Classifique (Avalie), de acordo com a escala contida na Tabela 2, as estratégias metodológicas utilizadas pelo livro didático para desenvolver o conceito de "Função logarítmica".

\begin{tabular}{|l|l|}
\hline Estratégia Metodológica & Classificação \\
\hline Referências à Matemática Pura & \\
\hline Referências à semirrealidade & \\
\hline
\end{tabular}




\section{Referências à realidade}

9) Qual o grau de abordagem, dado pelo livro didático, acerca das conexões entre a Tecnologia da Informação e a Educação Matemática?

\begin{tabular}{|l|l|l|l|l|}
\hline Conceito & Insatisfatório & $\begin{array}{l}\text { Parcialmente } \\
\text { satisfatório }\end{array}$ & Satisfatório & $\begin{array}{l}\text { Altamente } \\
\text { satisfatório }\end{array}$ \\
\hline Definição de Função & & & & \\
\hline Função afim & & & & \\
\hline Função quadrática & & & & \\
\hline Função exponencial & & & & \\
\hline Função logarítmica & & & & \\
\hline
\end{tabular}

10) Qual o grau de abordagem, dado pelo livro didático, acerca das conexões entre a Tecnologia da Informação e a Sociedade?

\begin{tabular}{|l|l|l|l|l|}
\hline Conceito & Insatisfatório & $\begin{array}{l}\text { Parcialmente } \\
\text { satisfatório }\end{array}$ & Satisfatório & $\begin{array}{l}\text { Altamente } \\
\text { satisfatório }\end{array}$ \\
\hline Definição de Função & & & & \\
\hline Função afim & & & & \\
\hline Função quadrática & & & & \\
\hline Função exponencial & & & & \\
\hline Função logarítmica & & & & \\
\hline
\end{tabular}

11) Os textos apresentados no livro didático possibilitam o desenvolvimento da habilidade de compreensão de aspectos associados à dimensão política, presentes na sociedade, por meio da(o) Educação (Ensino de) Matemática.

\begin{tabular}{|l|l|l|l|l|}
\hline Conceito & Insatisfatório & $\begin{array}{l}\text { Parcialmente } \\
\text { satisfatório }\end{array}$ & Satisfatório & $\begin{array}{l}\text { Altamente } \\
\text { satisfatório }\end{array}$ \\
\hline Definição de Função & & & & \\
\hline Função afim & & & & \\
\hline Função quadrática & & & & \\
\hline Função exponencial & & & & \\
\hline Função logarítmica & & & & \\
\hline
\end{tabular}

12) Os exercícios apresentados no livro didático possibilitam o desenvolvimento da habilidade de compreensão de aspectos associados à dimensão política, presentes na sociedade, por meio da (o) Educação (Ensino de) Matemática.

\begin{tabular}{|l|l|l|l|l|}
\hline Conceito & Insatisfatório & $\begin{array}{l}\text { Parcialmente } \\
\text { satisfatório }\end{array}$ & Satisfatório & $\begin{array}{l}\text { Altamente } \\
\text { satisfatório }\end{array}$ \\
\hline Definição de Função & & & & \\
\hline Função de afim & & & & \\
\hline Função de quadrática & & & & \\
\hline Função exponencial & & & & \\
\hline Função logarítmica & & & & \\
\hline
\end{tabular}

13) Classifique, de acordo com a escala contida na Tabela 1 , se o livro didático apresenta propostas que estimulam a participação em equipe, afim de desenvolver a democracia. 


\begin{tabular}{|l|l|}
\hline Definição de Função & \\
\hline Função afim & \\
\hline Função quadrática & \\
\hline Função exponencial & \\
\hline Função logarítmica & \\
\hline
\end{tabular}

14) Classifique, de acordo com a escala contida na Tabela 1 , se o livro didático, apresenta propostas que possibilitam o desenvolvimento da competência democrática.

\begin{tabular}{|l|l|}
\hline Conceito & Classificação \\
\hline Definição de Função & \\
\hline Função afim & \\
\hline Função quadrática & \\
\hline Função exponencial & \\
\hline Função logarítmica & \\
\hline
\end{tabular}

15) Classifique, de acordo com a escala contida na Tabela 1, se as diferentes seções do livro didático, relacionados ao conceito de função, apresentam informações associadas aos termos-chave competência crítica, distância crítica e engajamento crítico.

\begin{tabular}{|c|c|c|c|}
\hline Seções & $\begin{array}{c}\text { Competência } \\
\text { Crítica }\end{array}$ & $\begin{array}{c}\text { Distância } \\
\text { Crítica }\end{array}$ & $\begin{array}{c}\text { Engajamento } \\
\text { Crítico }\end{array}$ \\
\hline Textos introdutórios & & & \\
\hline Textos específicos & & & \\
\hline Exercícios & & & \\
\hline Curiosidades & & & \\
\hline Informações adicionais & & & \\
\hline
\end{tabular}

16) Classifique, de acordo com a escala contida na Tabela 1, se as diferentes seções do livro didático, relacionados ao conceito de função afim, apresentam informações associadas aos termos-chave competência crítica, distância crítica e engajamento crítico.

\begin{tabular}{|c|c|c|c|}
\hline Seções & $\begin{array}{c}\text { Competência } \\
\text { Crítica }\end{array}$ & $\begin{array}{c}\text { Distância } \\
\text { Crítica }\end{array}$ & $\begin{array}{c}\text { Engajamento } \\
\text { Crítico }\end{array}$ \\
\hline Textos introdutórios & & & \\
\hline Textos específicos & & & \\
\hline Exercícios & & & \\
\hline Curiosidades & & & \\
\hline Informações adicionais & & & \\
\hline
\end{tabular}

17) Classifique, de acordo com a escala contida na Tabela 1, se as diferentes seções do livro didático, relacionados ao conceito de função quadrática, apresentam informações associadas aos termos-chave competência crítica, distância crítica e engajamento crítico.

\begin{tabular}{|c|c|c|c|}
\hline Seções & $\begin{array}{c}\text { Competência } \\
\text { Crítica }\end{array}$ & $\begin{array}{c}\text { Distância } \\
\text { Crítica }\end{array}$ & $\begin{array}{c}\text { Engajamento } \\
\text { Crítico }\end{array}$ \\
\hline Textos introdutórios & & & \\
\hline
\end{tabular}




\begin{tabular}{|c|l|l|l|}
\hline Textos específicos & & & \\
\hline Exercícios & & & \\
\hline Curiosidades & & & \\
\hline Informações adicionais & & & \\
\hline
\end{tabular}

18) Classifique, de acordo com a escala contida na Tabela 1 , se as diferentes seções do livro didático, relacionados ao conceito de função exponencial, apresentam informações associadas aos termos-chave competência crítica, distância crítica e engajamento crítico.

\begin{tabular}{|c|c|c|c|}
\hline Seções & $\begin{array}{c}\text { Competência } \\
\text { Crítica }\end{array}$ & $\begin{array}{c}\text { Distância } \\
\text { Crítica }\end{array}$ & $\begin{array}{c}\text { Engajamento } \\
\text { Crítico }\end{array}$ \\
\hline Textos introdutórios & & & \\
\hline Textos específicos & & & \\
\hline Exercícios & & & \\
\hline Curiosidades & & & \\
\hline Informações adicionais & & & \\
\hline
\end{tabular}

19) Classifique, de acordo com a escala contida na Tabela 1 , se as diferentes seções do livro didático, relacionados ao conceito de função logarítmica, apresentam informações associadas aos termos-chave competência crítica, distância crítica e engajamento crítico.

\begin{tabular}{|c|c|c|c|}
\hline Seções & $\begin{array}{c}\text { Competência } \\
\text { Crítica }\end{array}$ & $\begin{array}{c}\text { Distância } \\
\text { Crítica }\end{array}$ & $\begin{array}{c}\text { Engajamento } \\
\text { Crítico }\end{array}$ \\
\hline Textos introdutórios & & & \\
\hline Textos específicos & & & \\
\hline Exercícios & & & \\
\hline Curiosidades & & & \\
\hline Informações adicionais & & \multicolumn{2}{|c|}{} \\
\hline
\end{tabular}

20) Classifique, de acordo com a escala contida na Tabela 1 , se o livro didático, ao abordar os seguintes conceitos, contribui para o desenvolvimento do conhecimento tecnológico.

\begin{tabular}{|c|c|}
\hline Conceito & Classificação \\
\hline Definição de Função & \\
\hline Função afim & \\
\hline Função quadrática & \\
\hline Função exponencial & \\
\hline Função logarítmica & \\
\hline
\end{tabular}

21) Classifique, de acordo com a escala contida na Tabela 1, se o livro didático, ao abordar os seguintes conceitos, contribui para o desenvolvimento do conhecimento reflexivo.

\begin{tabular}{|c|c|}
\hline Conceito & Classificação \\
\hline Definição de Função & \\
\hline Função afim & \\
\hline Função quadrática & \\
\hline Função exponencial & \\
\hline
\end{tabular}




\section{Função logarítmica}

22) Classifique, de acordo com a escala contida na Tabela 1, se o manual do professor apresenta informações associadas ao desenvolvimento do conhecimento tecnológico do aluno.

\begin{tabular}{|c|c|}
\hline Manual do professor & Classificação \\
\hline Textos sobre educação & \\
\hline Sugestões de leitura & \\
\hline Textos específicos & \\
\hline Resolução de exercícios & \\
\hline
\end{tabular}

23) Classifique, de acordo com a escala contida na Tabela 1 , se o manual do professor apresenta informações associadas ao desenvolvimento do conhecimento reflexivo do aluno.

\begin{tabular}{|c|c|}
\hline Manual do professor & Classificação \\
\hline Textos sobre educação & \\
\hline Sugestões de leitura & \\
\hline Textos específicos & \\
\hline Resolução de exercícios & \\
\hline
\end{tabular}

24) Classifique, de acordo com a escala contida na Tabela 1, se o manual do professor apresenta informações associadas ao desenvolvimento da competência democrática do aluno.

\begin{tabular}{|c|c|}
\hline Manual do professor & Classificação \\
\hline Textos sobre educação & \\
\hline Sugestões de leitura & \\
\hline Textos específicos & \\
\hline Resolução de exercícios & \\
\hline
\end{tabular}

25) Classifique, de acordo com a escala contida na Tabela 1, se o livro didático e o manual do professor, apresentam propostas que abordam os conjuntos de ideias que estruturam a Educação Matemática Crítica.

\begin{tabular}{|c|c|}
\hline Ideias & Classificação \\
\hline Sociedade altamente tecnológica & \\
\hline Educação Crítica & \\
\hline Dimensão política & \\
\hline Competência democrática & \\
\hline
\end{tabular}

26) Classifique, de acordo com a escala contida na Tabela 1, se o livro didático e o manual do professor, apresentam propostas que contribuam para 0 desenvolvimento da Educação Matemática Crítica.

\begin{tabular}{|c|c|}
\hline Livro & Classificação \\
\hline & \\
\hline
\end{tabular}




\subsection{Critérios de Análise de Dados}

O instrumento de avaliação descrito acima foi elaborado com a intenção de analisar três dos sete livros didáticos mais adotados pelas escolas participantes do PNLD 2015. Os livros foram selecionados aleatoriamente.

A Tabela 1 foi criada com a intenção de estruturar a análise e a coluna "Percentual" indica o quantificador do descritor para o item avaliado.

No instrumento de avaliação construído, em algumas questões, foram utilizadas as referências apresentadas por Skovsmose (2000) para investigar as situações abordadas. A expressão 'Referências à Matemática Pura' refere-se às "questões e atividades matemáticas que podem se referir à matemática e somente a ela" (SKOVSMOSE, 2000, p. 7), representando casos não contextualizados, que estão inseridos apenas na Matemática, sem nenhuma referência com a realidade. Já a expressão 'Referências à semirrealidade' "não se trata de uma realidade que 'de facto' observamos, mas uma realidade construída" (SKOVSMOSE, 2000, p. 7) e por fim, as 'Referências à realidade', onde professores e alunos podem trabalhar com situações que de fato acontecem e fazem parte do mundo real. Nas questões relacionadas ao manual do professor, em suas respectivas tabelas, foram excluídas a parte de sugestões de leitura, uma vez que os manuais dos professores não apresentam informações suficientes sobre os conteúdos dos livros sugeridos, além de conter muitas sugestões, portanto tornando inviável uma análise mais aprofundada das obras sugeridas.

A análise dos livros foi desenvolvida em quatro grupos - dos quais foram investigados os resultados das questões de um a vinte e quatro do instrumento de avaliação - com o auxílio de ferramentas da Estatística Descritiva para obtenção da resposta da vigésima quinta pergunta que direcionará para, finalmente, responder se o livro didático contribui ou não para o desenvolvimento da Educação Matemática Crítica (última questão).

O movimento da EMC é permeado por esses quatro grupos, o qual se acredita que para seu desenvolvimento pleno é importante a compreensão 
desses quatro pilares. A Tabela 2 fornece quais questões estão associadas aos grupos 1, 2, 3 e 4 .

Tabela 2. Constructos associados às questões

\begin{tabular}{|l|l|l|}
\hline Constructos & Grupos & Questões \\
\hline $\begin{array}{l}\text { Compreensão de uma sociedade altamente } \\
\text { tecnológica }\end{array}$ & 1 & 9 e 10. \\
\hline $\begin{array}{l}\text { Desenvolvimento dos Pressupostos da } \\
\text { Educação Crítica (EC) }\end{array}$ & 2 & $1,15,16,17,18,19$. \\
\hline $\begin{array}{l}\text { Compreensão da dimensão política da } \\
\text { Educação Matemática }\end{array}$ & 3 & $2,3,4,5,6,7,8,11$ e 12. \\
\hline Desenvolvimento da competência democrática & 4 & $13,14,20,21,22,23,24$. \\
\hline
\end{tabular}

Fonte: Elaborada pelos autores

O GRUPO 1 será composto pelas questões que abordam a compreensão de uma sociedade altamente tecnológica, uma vez que Skovsmose (2001) destaca a importância da Matemática em uma sociedade altamente tecnológica no sentido de que a Matemática tem um papel notável para o futuro de uma sociedade mediada pelas Tecnologias da Informação, qual seja "formatar a sociedade".

O GRUPO 2 será composto pelas questões que abordam as ideias da EC, pois as concepções de EMC sugiram por meio da EC. Skovsmose (2001) frisa a relevância dos aspectos presentes na EC também pertencerem à EMC.

O GRUPO 3 será composto pelas questões que abordam aspectos associados à dimensão política presentes na sociedade dado que ao utilizar a EMC como viés para o desenvolvimento do conhecimento matemático, de acordo com Skovsmose (1994), tal utilização poderá promover a participação crítica do indivíduo na sociedade tendo a visão de como a Matemática serve de suporte tecnológico para a resolução de problemas em situações cotidianas (envolvendo questões associadas à política, à economia etc.) para que o mesmo possa exigir seus direitos.

O GRUPO 4 será composto pelas questões ligadas especificamente à EMC e o desenvolvimento da competência democrática que, de acordo com Skovsmose (2001), é uma das principais funções da escola ao formar o aluno participante de uma sociedade democrática, visto que com o desenvolvimento 
dessa competência pode-se julgar de forma crítica as pessoas que estão no poder representando a população.

\subsection{Analisando algumas situações a partir do Instrumento de Avaliação construído}

3.3.1 Situação 1: A primeira questão que iremos demonstrar foi retirada do livro Matemática Paiva.

Figura 2: Questão analisada

29

Mais divulgou o balanço da inflação em determinado ano, apresentando o seguinte gráfico ao lado.

a) Qual foi a taxa percentual de inflação no mês 4 ? $7 \%$

b) Qual foi a menor taxa percentual de inflação nesse período? $5 \%$

c) De quantos por cento aumentou a inflação do mês 1 para o mês 3? $3 \%$

d) Construa uma tabela que apresente os meses de 1 a 12 e os valores correspondentes das taxas de inflação observadas no gráfico ao lado. e) A taxa de inflação é função do tempo? Por quê?

Fonte: Paiva (2013).

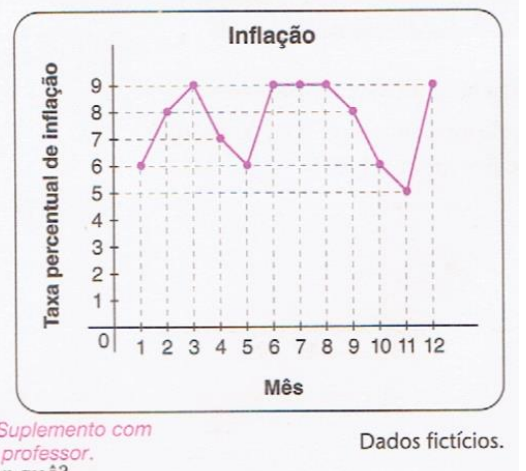

A análise que faremos será pautada apenas nos aspectos explícitos da questão, uma vez que os aspectos implícitos estão associados à percepção de cada professor, ou seja, o exercício não menciona a possibilidade de realizar uma pesquisa envolvendo a inflação na região do aluno, mas o professor poderia utilizar a questão para fomentar tal discussão. Este seria o exemplo de um aspecto implícito. Cabe destacar que para cada uma das situações analisadas aqui, avaliaremos a contribuição delas para os constructos mencionados na Tabela 2.

Posto isso, a Situação 1 aparece no capítulo destinado ao conceito de Função, está situada no referencial da Semirrealidade no ambiente tipo (3), considerando que esses dados não ocorreram de fato (o próprio enunciado informa que se tratam de dados fictícios) e a Situação 1 é exposta por meio de um problema fechado. 
A Situação 1 não apresenta relações acerca das conexões entre a Tecnologia da Informação e a Educação Matemática e entre a Tecnologia da Informação e a Sociedade. Consequentemente, a questão não contribui para o constructo "Compreensão de uma sociedade altamente tecnológica".

Em relação ao constructo "Desenvolvimento dos Pressupostos da Educação Crítica (EC)" a Situação 1 faria parte da análise da questão Q15, seção Exercícios, que avalia se as diferentes seções do livro do aluno, relacionados ao conceito de função, apresentam informações associadas aos termos-chave competência crítica, distância crítica e engajamento crítico. Esta situação não contribui para os três termos-chave presentes na EC.

Em relação ao constructo "Compreensão da Dimensão Política da Educação Matemática" a Situação 1 não contribui para o desenvolvimento da habilidade de criar modelos matemáticos (Q2), tampouco estimula maneiras criativas de estruturar e resolver problemas reais (Q3), uma vez que os alunos conseguem resolver o exercício apenas observando o gráfico presente no próprio enunciado.

Como já fora mencionado anteriormente, a Situação 1 está no capítulo referente ao conceito de funções e se enquadra no referencial da Semirrealidade (Q4). No que diz respeito à (Q12) a Situação 1 contribui para a compreensão da dimensão política presentes na sociedade, por meio da Educação Matemática.

Por fim, em relação ao constructo "Desenvolvimento da Competência Democrática" a Situação 1 não estimula a participação em equipe, afim de desenvolver a democracia (Q13), por consequência não possibilita o desenvolvimento da competência crítica (Q14), do conhecimento tecnológico (Q20) e do conhecimento reflexivo (21). Portanto, a Situação 1 não contribui para o "Desenvolvimento da Competência Democrática".

3.3.2 Situação 2: A segunda questão que iremos demonstrar foi retirada do livro Conexões com a Matemática.

Figura 3: Questão analisada

27. Dada a função dada por $\mathrm{f}(\mathrm{x})=\log _{2}(x+1)$, determine:
a) $f(7)$
b) $f(0)$
c) $f(-0.5)$ 
$\begin{array}{lll}\text { d) } f(\sqrt{2}-1) & \text { e) } f(-0.75) & \text { f) } f(63)\end{array}$

Fonte: Leonardo (2013)

A Situação 2 aparece no capítulo destinado à Função Logarítmica, está situada no referencial da Matemática Pura, no ambiente tipo (3) [esse tipo de situação foi encontrado em diversos momentos nos três livros] e é exposta por meio de um problema fechado. Apenas com a aplicação da fórmula o aluno consegue obter a resposta correta, não há estímulo a reflexões e há apenas uma resposta correta, que não proporciona discussões mais críticas.

A Situação 2 não apresenta relações acerca das conexões entre a Tecnologia da Informação e a Educação Matemática e entre a Tecnologia da Informação e a Sociedade. Consequentemente, a questão não contribui para o constructo "Compreensão de uma sociedade altamente tecnológica".

Em relação ao "constructo do Desenvolvimento dos Pressupostos da Educação Crítica (EC)" a Situação 2 faria parte da análise da questão Q19, seção Exercícios, que avalia se as diferentes seções do livro do aluno, relacionados à função logarítmica, apresentam informações associadas aos termos-chave competência crítica, distância crítica e engajamento crítico. Esta situação não contribui para os três termos-chave presentes na EC.

Em relação ao constructo "Compreensão da Dimensão Política da Educação Matemática" a Situação 2 não contribui para o desenvolvimento da habilidade de criar modelos matemáticos (Q2), tampouco estimula maneiras criativas de estruturar e resolver problemas reais (Q3), uma vez que os alunos conseguem resolver essa situação apenas aplicando a fórmula presente no próprio enunciado. A situação está no capítulo referente à Função Logarítmica e se enquadra no referencial da Matemática Pura (Q8) e não contribui para a compreensão da dimensão política presentes na sociedade por meio da Educação Matemática.

Por fim, em relação ao constructo "Desenvolvimento da Competência Democrática" a Situação 2 não estimula a participação em equipe, afim de desenvolver a democracia (Q13), por consequência não possibilita o 
desenvolvimento da competência crítica (Q14), do conhecimento tecnológico (Q20) e do conhecimento reflexivo (21). Portanto, a Situação 2 não contribui para o "Desenvolvimento da Competência Democrática".

3.3.3 Situação 3: A terceira questão que iremos demonstrar foi retirada do livro Matemática Dante.

Figura 4: Questão analisada

(UFRN) O gráfico a seguir representa a taxa de desemprego na Grande São Paulo, medida nos meses de abril, segundo o Dieese:

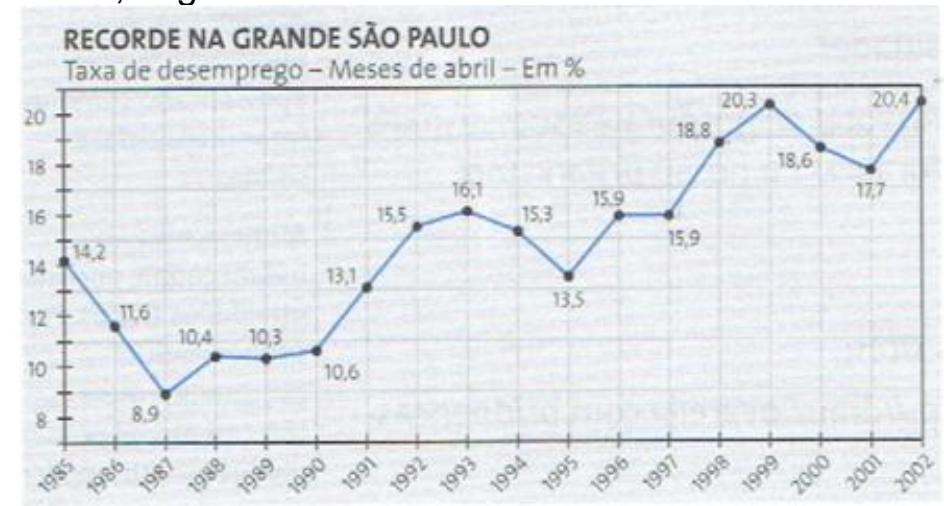

Analisando o gráfico, podemos afirmar que a maior variação na taxa de desemprego na Grande São Paulo ocorreu no período de:

a) abril de 1985 a abril de 1986 .

b) abril de 1995 a abril de 1996.

c) abril de 1997 a abril de 1998.

d) abril de 2001 a abril de 2002.

Fonte: Carta Capital, 5 jun. 2002. Ano VIII, n. 192 apud Dante (2014).

A Situação 3 aparece no capítulo destinado ao conceito de Função, está situada no referencial da Realidade no ambiente tipo (5) e é apresentada por meio de uma situação fechada, a qual os alunos conseguem resolver apenas analisando o gráfico presente no enunciado, não há estímulo a reflexões e há apenas uma resposta correta sem proporcionar discussões mais críticas.

A Situação 3 não apresenta relações acerca das conexões entre a Tecnologia da Informação e a Educação Matemática e entre a Tecnologia da Informação e a Sociedade. Consequentemente, a questão não contribui para o constructo "Compreensão de uma sociedade altamente tecnológica".

Em relação ao constructo do Desenvolvimento dos Pressupostos da Educação Crítica $(E C)$ a Situação 3 faria parte da questão Q15, seção 
Exercícios, que avalia se as diferentes seções do livro do aluno, relacionados ao conceito de Função, apresentam informações associadas aos termos-chave competência crítica, distância crítica e engajamento crítico. Esta situação não contribui para os três termos-chave presentes na EC.

Em relação ao constructo da Compreensão da Dimensão Política da Educação Matemática a Situação 3 não contribui para o desenvolvimento da habilidade de criar modelos matemáticos (Q2), tampouco estimula maneiras criativas de estruturar e resolver problemas reais (Q3), uma vez que os alunos conseguem resolver o exercício apenas observando o gráfico presente no próprio enunciado.

A situação está no capítulo referente ao conceito de funções e se enquadra no referencial da Realidade (Q4). No que diz respeito à (Q12) a Situação 3 contribui para a compreensão da dimensão política presentes na sociedade por meio da Educação Matemática.

Por fim, em relação ao constructo "Desenvolvimento da Competência Democrática" a Situação 3 não estimula a participação em equipe, afim de desenvolver a democracia (Q13), por consequência não possibilita o desenvolvimento da competência crítica (Q14), do conhecimento tecnológico (Q20) e do conhecimento reflexivo (21). Portanto, a Situação 3 não contribui para o "Desenvolvimento da Competência Democrática".

\section{Considerações Finais}

A aplicação do produto "O Programa Nacional do Livro Didático. Do conceito de Função à Função Logarítmica: um olhar sociocrítico" construído a partir dos referenciais teóricos (Modelagem Matemática, Educação Matemática Crítica e Cenários para investigação) pode contribuir para que os docentes de Matemática da Educação Básica tenham uma visão mais crítica em relação ao material utilizado em suas aulas, analisando, neste contexto, se o livro didático utilizado por eles apresenta os elementos estruturantes necessários para uma formação crítica do estudante à luz da Educação Matemática Crítica. 
Em nossa pesquisa constatamos que os três livros analisados e que fazem parte do grupo dos mais adotados pelas escolas do Ensino Médio no Brasil, participantes do Programa Nacional do Livro Didático (PNLD), apresentam abordagem insatisfatória no que diz respeito ao desenvolvimento de atividades que potencializam a Educação Matemática Crítica.

\section{Referências}

ARAÚJO, Jussara de Loiola. Educação da Matemática Crítica: Reflexões e Diálogos. Argvmentvm: Belo Horizonte, MG, 2007.

Uma abordagem sócio-crítica da modelagem matemática: a perspectiva da educação matemática crítica. Alexandria Revista de Educação em Ciência e Tecnologia, Florianópolis, v. 2, n. 2, p. 55-68, 2009.

BARBOSA, Jonei Cerqueira. Modelagem na Educação Matemática: contribuições para o debate teórico. In: 24를 Reunião Anual da ANPED. Caxambu, MG, 2001. Disponível em: www.anped.org.br/reunioes/24/t1974438136242.doc.

BITTENCOURT, Circe. Livro didático e saber escolar: 1810-1970. Autentica: Belo Horizonte, MG, 2004.

DANTE, Luiz Roberto. Matemática: Contexto \& Aplicações. 2. ed. Ática: São Paulo, SP, 2013.

FAUSTINO, Ana Carolina; PASSOS, Carmen Lúcia Brancaglion. Cenários para investigação e resolução de problemas: reflexões para possíveis caminhos. Revista Educação e Linguagens, v. 2, p. 62-74, 2013.

GÉRARD, François-Marie; ROEGIERS, Xavier. Como conceber e avaliar manuais escolares. Portugal: Porto Codex: Porto, 1998.

LEONARDO, Fabio Martins de. Conexões com a Matemática. 2. ed. Moderna: São Paulo, SP, 2013.

PAIVA, Manoel. Matemática: Paiva. 2. ed. Moderna: São Paulo, SP, 2013.

SKOVSMOSE, Ole. Cenários para Investigação. Bolema. Ano 13, n. 14. Trad. De Jonei Cerqueira Barbosa. Rio Claro: Departamento de Matemática, Unesp, 2000, p. 66-91.

Critical mathematics education: some philosophical remarks. In: International Congress on Mathematics Education. Selected lectures. Sevilha: S. A. E. M., p. $413-425,1996$. 
http://dx.doi.org/10.5965/2357724X06112018392

Educação Matemática Crítica: a questão da democracia. 2. ed. Tradução de Abgail Lins e Jussara de Loiola Araújo. Campinas, SP: Editora Papirus, 2001. 